Balanced Leadership: a New Perspective for Leadership in Organizational Project Management

\author{
By Ralf Müller, Johann Packendorff and Shankar Sankaran
}

\begin{abstract}
This chapter addresses a new perspective towards leadership, that of balanced leadership in organizational project management. The chapter starts with an overview of existing theoretical perspectives of leadership and leaders, where we introduce the distinction between leadership intent as an intra-personal process and practiced leadership as an inter-personal process of influencing. We discuss some of the popular theories in light of this distinction. Then we address the need for balanced leadership, which we propose as the temporary adjustment of leadership exercised by the project manager (vertical leadership) with leadership by one or several team members (horizontal leadership), and the situational particularities that emphasize the appropriateness of one approach over the other. We subsequently develop a four-step process of selecting, enabling, exercising, and controlling for balanced leadership and outline the intra and inter-personal activities for vertical and horizontal leaders in each of these steps. This provides an in-depth overview of the type and scope of inter and intra-personal leadership activities and their synchronization needs for coordinated balanced leadership to happen. Readers learn to look at leadership in and across projects as a combination of horizontal and vertical approaches, distributed in a coordinated way between vertical and horizontal leaders in organizational project management.
\end{abstract}

\title{
Introduction
}

Leadership is an interpersonal, person-oriented, social influence (Endres \& Weibler, 2016), which guides in direction, course, action, and opinion (Bennis \& Nanus, 1985). To that end it is different from management, which is task oriented in the sense of bringing about or accomplishing something, being responsible for, or conducting something (Bennis \& Nanus, 1985).

Leadership requires a leader, but leaders do not operate in a vacuum, nor do they need to be formal managers. For a long time the terms 'leader', 'leadership' and 'manager' were used almost interchangeably, and only recent years brought a distinction in their use (Alvesson \& Sveningsson, 2003; Crevani et al, 2010). The development of leadership research over the years has also focused on different aspects of leadership, ranging from an interest in the traits, characteristics and competencies of individual leaders, to an interest in how leadership is practiced in social settings by leaders, coleaders and followers in interaction (Carroll et al, 2008).

Recent years have brought much insight about the importance of leadership as a complement to management in projects and has added a variety of perspectives towards leadership. Examples include the traditional view of project and program managers as leaders and their associated leadership style. This person-centric perspective has addressed the particular leadership styles of these roles (e.g. Keegan \& Den Hartog, 2004) as well as personal characteristics that bring about certain leadership styles (e.g. Dulewicz \& Higgs, 2005). We call this the vertical leader and his or her leadership style.

Other research has looked at leadership that emerges from teams or individuals in a team and complements the leadership of the vertical leader. Examples for this include the studies on shared leadership (Pearce \& Conger, 2003; Crevani et al, 2007) and its related processes (e.g. Cox, Pearce, \& Perry, 2003). We call this approach the horizontal leader and his, her or their leadership style.

Most recently, researchers have started to investigate the balance and situational contingency of vertical and horizontal leadership in projects. They showed the particular circumstances under which vertical leaders in projects make way for horizontal leaders to temporarily partake in leading the project (e.g. Müller et al., 2016). We call this balanced leadership, i.e. a situation in which the balance between vertical and horizontal leadership is appropriate. 
In this chapter, we acknowledge and integrate these different perspectives by distinguishing between a person's intent and the leadership the person is practicing in interaction with others. Here leader intent addresses the related intra-personal processes and activities that are carried out by the leader prior to exercising leadership to others in practice. Practiced leadership is the subsequent social exchange as defined above, thus a social exchange or inter-personal activity between the leader and the follower(s). Combining this distinction with the perspectives of vertical and horizontal leadership identifies:

- Leader intent by the vertical and horizontal leaders as personal internal processes, antecedent of their social interaction known as practiced leadership

- Practiced leadership by the vertical and horizontal leaders, as a social exchange that exercises influence on one or several team members

In this chapter, we address the interaction of leader intent (both vertically and horizontally) and practiced leadership (both vertically and horizontally) in the context of balanced leadership in projects. We model this interaction in order to clarify the different stages of balanced leadership and their nature as being intra-personal (leader intent) or inter-personal (practiced leadership).

\section{Balanced leadership}

Balanced leadership happens when the vertical leader temporarily enables and allows for horizontal leadership to happen in situations, for example taking a lead on a problem that a team member is an expert on, where it is seen as advantageous for the project. This typically happens for a short period in a project, after which the vertical leader assumes his or her role as leader again. Horizontal leadership is the social process through which one or several members of the project team influence the project manager and the rest of the team (and potentially other stakeholders) to carry the project forward in a particular way. For example a team member may highlight a risk that the project manager has overlooked but the team member became aware of. Accordingly, we define vertical leadership as the inter-personal process through which the project or program manager influences the team and other stakeholders, to carry the project forward.

There are three criteria that influence the emergence of balanced leadership in projects (Müller et al., 2016):

1. The vertical leader's attitude towards horizontal leadership. Some project managers, in their role as vertical leaders, are skeptical about the idea of surrendering authority to a team member. Reasons include, that they are appointed as project manager because of their superior knowledge. Granting leadership rights to members of the team might compromise their perceived status. Others see themselves as "in charge" and like to have full control over the developments in the project. Hence, the presence of balanced leadership depends on the vertical leader's attitude towards horizontal leadership.

2. The nature of the leadership situation. Empirical studies show that those project managers who allow for horizontal leadership often limit the scope and authority to merely questions of technical nature, and only those areas of decision making that do not influence the project's objectives in terms of time, cost and scope. Hence, they retain the right as sole leader in those aspects that influence their project manager objectives and status.

3. The trust that the vertical leader has in one or several members of the team to lead successfully or contribute effectively to the management of the project. Trust is the "willingness of a party to be vulnerable to the actions of another party based on the expectation that the other will perform a particular action important to the trustor, irrespective of the ability to monitor or control that other party" (Mayer, Davis, \& Schoorman, 1995, p. 712). Project team members gain the trust of the project manager through particular competences of which the project manager becomes aware through reputation, interaction and monitoring or through earlier collaboration.

Given the restriction that horizontal leadership is most often limited to situations requiring leadership in technical aspects of the project, it is typically a technical competence that makes individuals or subteams trusted by the project manager. This trust manifest itself in several ways. Trusted members are 
often assigned additional tasks, which are typically also of technical nature (Müller et al., 2016). In these tasks, the trusted members can develop and show their self-leadership capabilities (Cox et al., 2003). The latter is required for acceptance by the other team members and the project manager, once a situation for their horizontal leadership arises. That means, a team member must first learn to lead himself or herself before being accepted by other team members as horizontal leader (Manz, 1986). In addition, the empowerment through the project manager indicates to the rest of the project team the trusted status of the particular team member. This contributes to the other team members' shared mental model of "who can do what" in a project. This mental model is a further requirement for horizontal leadership to function, as this model allows deciding when to transfer leadership from one member to another (Burke, Fiore, \& Salas, 2003).

In summary, we can say that the balance between vertical and horizontal leadership is enabled through the project manager by empowerment of one or several potential horizontal leaders. The balance between leading vertical and horizontal takes place in a cognitive space of the project manager and team members where the nature of empowerment, the self management of the empowered, and the shared mental model of the team members' capabilities interact for the determination of the scope of this balance (Müller et al., 2016).

\section{Vertical leaders and their leadership}

Project and program mangers, in their role as vertical leaders, possess authority, which manifests itself in their simultaneous management and leadership. Contingent on the particular situation they increse the extent of management or leadership based on the situation (Müller \& Turner, 2010b). In this chapter, we do not address the management side but focus on the leadership side. On the leadership side, we address leadership intent as the intra-personal self-leading of leaders, which is difficult to observe, and inter-personal practiced leadership as a social exchange process, which is easier to observe.

Research on vertical leaders has been done for thousands of years. For example Confucius described the four virtues of leaders in 500 B.C. as relationships (jen), values (xiao), process (li), and moderation (zhang rong) (Collinson, 2000). Thus, it reflects the intra-personal leading as discussed above. 200 years later Aristoteles turned the perspective from the leader to inter-personal leadership by outlining the process of building relationships (pathos), selling of values (ethos) and then, and only then, persuade with logic (logos) as the way to lead people. 2,300 years later we find this process still being used in sales and other related management trainings (Müller \& Turner, 2010b).

Intra-personal leader literature of the more recent decades describes project managers often in terms of their traits, such as an integrator with a good understanding of technology, who is able to bridge towards administration and other parts of the organization (Gaddis, 1959). Others describe them as a problem solver, results oriented leader, energetic, self-confident, strategic thinker with good communication and negotiation abilities (Turner, 2009). Yet others portray them as thick-skinned pragmatist (Hauschildt, Keim \& Medcof, 2000)

Another set of literature looked at the personality of project and program managers in an attempt to identify the impact of personality on inter-personal leadership styles. For example, Dulewicz and Higgs (2003) developed 15 dimensions of leadership competences and clustered them under emotional (EQ), intellectual (IQ) and managerial (MQ) leadership competences. They showed that different personality combinations of these competences lead to different leadership styles, and these styles fit differently to organizational change projects of various levels of complexity. For that, they linked the particular combinations of project managers to three different leadership styles:

- Goal oriented style, which is similar to transactional style, and is most effective on low complexity projects. These leaders possess high levels IQ and medium to high levels of EQ and MQ

- Involving style, which is similar to the transformational style, and is most effective on medium complexity projects. These leader show high levels of EQ and medium levels of IQ and MQ. 
- Engaging style, which is best on high complexity projects and often applied by managers with high levels of EQ and MQ, and medium levels of IQ.

A different view emerged through the investigation of the link between these leadership competences and project success (Müller \& Turner, 2010b). Here the success of:

- Engineering and construction projects is strongly impacted by project managers with sense of duty and good interpersonal communication skills. This is characteristic or project managers who have a) conscientiousness (a EQ competence), that is, a clear commitment to a course of action in the face of challenges, shown by matching 'words with deeds' and encouraging others to support the chosen direction, and b) interpersonal sensitivity (another EQ competence), which is the awareness of, and taking into account of, the needs and perceptions of others in arriving at decisions and proposing solutions to problems and challenges. The former constitutes an intra-personal leading characteristic and the latter an inter-personal leadership characteristic.

- Information Technology and Telecom projects requires finding the right 'tone' with others, together with a project manager's good control over the own feelings and helping project team members to take on challenging tasks. This is characteristic of project managers who are a) aware of their own feelings and able to recognize them (an EQ competence), b) approachable and accessible, engaging others to win their support through communication tailored for each audience (a MQ competence), and c) encourage others to take on ever more demanding tasks and roles (a MQ competence). Here the first is an intra-person leading characteristics, whereas the latter two characteristics are inter-person leadership characteristics.

- Business and organizational change projects require project managers who actively create the required dynamics for change, together with accommodation of those involved. This is characteristic of project managers who are a) approachable and accessible, engaging others to win their support through communication tailored for each audience (a MQ competence), and motivated, as shown through their drive and energy to achieve clear results and make an impact. The former constitutes an inter-person leadership and the latter an intra-person leading characteristic.

Hence, leadership of projects requires vertical leaders who posses both intra-personal leading and inter-personal leadership characteristics.

Studies on leadership styles in projects often address transactional and transformational styles. Here transactional leadership emphasizes contingent rewards, that is, the team members are rewarded for meeting performance targets. These leaders typically only get involved when tasks are not going according to plan. Contrarily, transformational leaders exhibit charisma, develop a vision, engender pride, respect and trust, provide inspiration, motivate by creating high expectations and modelling of appropriate behaviors. They give consideration to the individual, pay personal attention to followers and give them respect (Bass, 1990). Hence, transactional leaders address the lower levels and transformational leaders the upper levels of Maslow's (1943) hierarchy of needs.

Keegan and den Hartog (2004) showed that project managers in average prefer transactional over transformational styles, which they found a bit strange in light of the uniqueness of projects. This would suggest that more transformational styles are applied. Later studies looked at leadership at different levels of project complexity, and identified transactional styles as prevalent in relatively simple, often maintenance and engineering type of projects, whereas transformational styles being preferred in the more complex and organizational change types of projects (Dulewicz \& Higgs, 2003; Müller \& Turner, 2010).

Summarizing the literature about the project and program manager as vertical leader, we see that the writers identified both intra-person leader intent characteristics as well as inter-person practiced leadership characteristics as pre-requisites for successful project management. However, the literature has been largely indifferent as to the differences between the two perspectives. In this chapter we extend this view by looking at the way these managers lead themselves as part of their overall role as leaders. 


\section{Horizontal leaders and their leadership}

Recent years have shown a diversity of new perspectives towards leadership in projects (cf Müller \& Turner, 2005; Lindgren \& Packendorff, 2009). They often originate in recent developments in general leadership theory, driven both by epistemological reorientations and empirical observations (cf Gronn, 2002; Cunliffe \& Eriksen, 2011; Drath et al, 2006; Pearce \& Conger, 2003; Raelin, 2011; Endres \& Weibler, 2016). The traditional vertical leadership approaches as described in the above section are thus increasingly supplemented by approaches also including horizontal and thereby collective leadership. The point is rarely to deny the existence of vertical leadership, but to point at that practical leadership work involves several actors simultaneously and that those actors do not necessarily have to be formal managers or leaders.

Horizontal and collective approaches to leadership studies share the notion that leadership should not be defined only as the actions taken by single, vertical leaders. Instead we must be open to the notion that leadership work involves many different actors and that such an insight provides us with opportunities to not only understand leadership practice better, but also to devise more effective ways of organizing leadership in complex, knowledge-intensive settings (Crevani et al, 2010) requiring, for example, organizational ambidexterity (Havermans et al, 2015). In their extensive overview, Denis et al (2012) identify four streams of research based in such a perspective, which we present here to also link to what it would mean in project situations:

(1) Sharing leadership for team effectiveness, that is, an approach focusing on members of a team and how they together may lead each other in pursuit of favorable outcomes (Pearce \& Conger, 2003). The basic stance is that it could be more effective to involve several team members in the management of the project, usually in situations characterized by high task interdependence and complexity. In such situations, a single vertical leader might not possess all the expertise and the control needed, but will play an important role in fostering effective shared leadership behaviors.

(2) Pooling leadership at the top to lead others. This approach is mainly concerned with top management echelons in organizations, emphasizing the positive effects of joint organizational leadership in terms of role specialization, complementarity and legitimacy (Gronn, 2002, Denis et al, 2001). Organizations within culture, media, higher education, health care, and software development often tend to make use of such leadership practices. If we consider a project to be a temporary organization, this approach would mean that dyadic or triadic project management constellations could be favorable in some circumstances, for example in projects operating across different technologies, industries or institutional logics.

(3) Spreading leadership across levels of time. This approach is concerned with processes where different individuals are involved in leading the project at different stages or episodes (Huxham \& Vangen, 2000). In project settings, this could be relevant for example in large infrastructure projects - which often go through several quite distinct stages with different actors and stakeholders being involved in the journey from idea to completion - where relaying leadership between different leaders could work better than having the same vertical leader running the entire process.

(4) Producing leadership through interactions. This approach disassociates leadership from distinct individuals, instead studying how leadership work is unfolding and practiced - thus locating leadership as something that emerges in interactions between team members rather than being exercised by these members. In a relational leadership view from an organizational perspective (Uhl-Bien 2006; 655) leadership is not viewed as a hierarchical position but 'as a process as relational dynamics throughout the organization' Such a relational view in projects would be concerned with how well interactions in a project team unfold, that is, to what extent issues, identities, time frames and spaces of action are thoroughly processed and understood in the team (Lindgren \& Packendorff, 2011; Packendorff et al, 2014). 
These streams of research are all of quite recent origin, but they have still resulted in a number of central concepts and perspectives in leadership research that are important to include in our analysis of balanced project leadership. We name a few exemplary perspectives.

\section{Shared leadership}

Shared leadership, or its related concept of distributed leadership, is closely linked to horizontal leadership, and complementary to vertical leadership in balanced leadership. This leadership emerges in projects when the situation requires the temporary and dedicated leadership by a specialist in the project team or several thereof (Pearce \& Sims, 2000). Cox, Pearce and Perry (2003) describe it as a collaborative, emergent process of group interaction. In this process, team members engage in peer leadership during collaboration (Crevani et al, 2007). It implies that team members have significant authority to chart the team's path forward, thus it requires empowerment granted by the vertical leader and self-management from those team member exercising shared leadership.

\section{Authentic leadership}

This addresses the intra-personal or felt experience of the followers with the intra-personal characteristics of the leader. For example when a leader is perceived to possess strong positive values, lead from the heart, set highest levels of ethics and morality, and goes beyond his or her personal interests for well-being of the followers, then he or she is often seen as authentic. Their leadership style is based on trust and motivated by the well-being of their followers. Through their intra-personal leading they build an environment of mutual trust, optimism, altruism, which is then reflected through inter-personal leadership based on trust, transparency, and openness. (Toor \& Ofori, 2008)

\section{Aesthetic Leadership}

This addresses the holistic felt experience of the follower and takes into account the influence of a leader together with a wide range of non-human aspects. It includes spaces, places and other influences received through the senses. Hence it perceives leadership to happen socio-materially by adding symbols, memories, feelings, physical qualities of places, as well other situational influences into a perceived leadership by the follower (Hansen, Ropo, \& Sauer, 2007). This perspective of leadership goes beyond the scope of the present chapter and is addressed, among others in the current research on the impact of physical space on leadership styles (e.g. in Paoli, Vaagaasar, \& Müller (2013).

\section{Distributed leadership}

While this concept is used differently in different contexts and sub-fields (Bolden, 2011; Cope et al, 2011) it has a common denominator in the view of leadership as a collective phenomenon, by default distributed on the actors involved, rather than an individual phenomenon emanating from a single vertical manager (Gronn, 2002). Applied to project leadership inquiry, it means that project leadership could be studied as activities emerging in the social interaction in and around the project team, acknowledging the leadership work done also by other team members and opening up empirical inquiries for a multitude of potentially differing views of the same processes. In these inquiries, leadership should be studied in terms of practices, that is, the everyday activities that constitute project leadership (Cicmil et al., 2006; Blomquist et al., 2010) with a focus on interaction processes as such rather than on in which formal organizational unit they unfold (Lindgren \& Packendorff, 2009).

When re-focusing from individual leaders to leadership processes, we are able to discern far wider social interactions in which project leadership is constructed. In the studies made by Lindgren \& Packendorff (2011) and Packendorff et al (2014) it appeared that several individuals, both inside and outside the companies, involved themselves in the ongoing construction of project direction. Instead of viewing, for example, changed technical priorities, agreements with inspection authorities or the division of duties at laboratories as formal decisions made by the project leader, far more complex interactions leading up to these decisions could be acknowledged in terms of leadership. When going beyond the formally defined project as unit of analysis, it could be observed that project leadership activities also involved actors that would elsewhere have been seen as more or less external 
stakeholders or part of the governance structure. Projects - or any other formal organizational unit for that matter - is important to actors in the sense that they are boundary constructs that contribute to a desired sense of order and clarity (Lundin \& Söderholm, 1995). That means that formally defined organizational boundaries are important to understand as constantly being co-constructed by actors, but that empirical fieldwork and analysis on, for example, leadership or organizing processes should not be confined to these very boundaries. Again, the formally designated project leader may be a part of leadership work 'external' to the project, just as 'external' actors may be a part of project leadership activities.

In a quantitative study of team effectiveness, Mehra et al (2006) investigated the effects of distributed versus vertical leadership and also the effects of coordination within a network of horizontal leaders. They concluded that distributed leadership forms could not be associated with higher performance per se, as the optimal balance between vertical and distributed leadership were different from situation to situation. Within the category distributed leadership configurations, however, it was clear that coordinated networks of horizontal leaders yielded better performances than fragmented networks thereby pointing at an important role for vertical leaders also in situations characterized by a high degree of horizontal leadership.

\section{Relational leadership}

Relational leadership (Fletcher, 2004; Uhl-Bien, 2006; Cunliffe \& Eriksen, 2011; Endres \& Weibler, 2016) is closely connected to the notion of leadership as essentially a distributed phenomenon, emerging in interaction between people. It is usually described in contrast to 'entitative' perspectives in which the focus of interest is placed on the individuals interacting. Central issues studied in this tradition are social interactions, usually from a social constructionist viewpoint. Examples include the exploration of how relational practices in organizations are developed, and how ethical and respectful ways of relating can be harnessed (Crevani, 2015).

Although the literatures concerned with different aspects of horizontal leadership are not as well established and empirically well-researched as those on vertical leadership, we can still make some concluding remarks on the issues of leader intent and practiced leadership. First, it is important to acknowledge that leader intent is not formed in a vacuum; it is formed in interaction with others and involves both traditional expectations on vertical leadership as well as expectations on performing responsible co-workership and exercising technical seniority/superiority. Second, practiced horizontal leadership will from time to time involve different sets of people depending on the situation at hand for example through different successive leadership configurations or through relaying leadership (Denis et al, 2012). Third, what is processed in the continuous construction of leader intent and practiced leadership are not only formal decisions on project planning, control and deliveries - but also organizational complexities, technical issues and identities (Lindgren \& Packendorff, 2011). The next section shows how the interaction of leader intent and practiced leadership can be modelled as a process.

\section{Modelling the interaction of leader intent and practiced leadership in balanced leadership}

The model is shown in Figure 1. It shows a sequential process that starts in quadrant 1 in the lower left with the qualification of possible candidates for horizontal leadership and the subsequent selection of a candidate when the need for horizontal leadership arises. Both activities are internal decisions by the two leaders. The potential horizontal leaders qualify themselves, for example, through reputation and/or superior performance or otherwise and make an intra-personal decision, often based on their self-efficacy, to accept or decline the offer to lead when being selected by the vertical leader. Similar is the intra-personal decision by the vertical leader to select one or a particular group as horizontal leader(s).

The empowerment of the horizontal leader(s) to their temporary role marks a social activity by the vertical leader and is addressed in quadrant 2 in the upper left of Figure 1. The vertical leader appoints (or grants the authority to) one or several horizontal leader(s). This activity is visible to the rest of the 
team and constitutes an inter-personal leadership activity on the side of the vertical leader. The person(s) empowered has now the chance to develop his or her self-management capabilities, thus need to develop internally to the extent that other team members will trust and accept the new horizontal leader, once he or she starts to exercise leadership.

Quadrant 3 in the upper right addresses the next step, that is, the leadership of both horizontal and vertical leaders. Here the vertical leader's handover of leadership authority and the associated acceptance by horizontal leaders becomes visible to the team (and potentially other stakeholders). The horizontal leader(s) take(s) on the devised role and exercise(s) their leadership. Now the leadership styles of the vertical and horizontal leaders need to be synchronized in front of the other members of the team and other stakeholders, and clashes need to be avoided.

Once the horizontal leaders have taken over, the vertical leader's monitoring and control of the horizontal leaders sets in, quadrant 4 , lower right. This is an internal leading activity by the vertical leader and continues until the horizontal leaders finish their temporary role and the leadership authority goes back to the vertical leader. Then the circle repeats itself for the next occasion of balanced leadership.

\begin{tabular}{|c|c|c|c|}
\hline \multirow{2}{*}{ 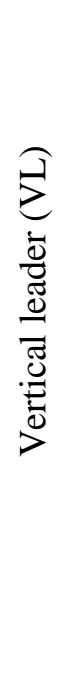 } & 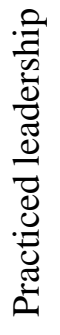 & $\begin{array}{l}\text { (2) Enabling: } \\
\text { VL: Empowering the vertical } \\
\text { leader } \\
\text { HL: Developing self } \\
\text { management }\end{array}$ & $\begin{array}{l}\text { (3) Exercising horizontal } \\
\text { leadership: } \\
\text { VL: Shifting leadership to HL } \\
\text { HL: Executing leadership. } \\
\text { Showing self management }\end{array}$ \\
\hline & 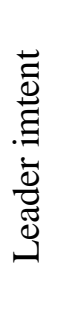 & $\begin{array}{l}\text { (1) Qualmuation and } \\
\text { selection: } \\
\text { VL: Selection of horizontal } \\
\text { leader } \\
\text { HL: Developing self-efficacy } \\
\text { capabilities }\end{array}$ & $\begin{array}{l}\text { (4) Monitoring and control: } \\
\text { VL: Monitoring and } \\
\text { controlling the HL } \\
\text { HL: Monitoring and } \\
\text { controlling the team }\end{array}$ \\
\hline & & Leader intent & Practiced leadership \\
\hline & & Horizont & ders (HL) \\
\hline
\end{tabular}

Figure 1: Leading and leadership, vertically and horizontally

In the following we discuss the model in more detail.

\section{(1) - Qualification and selection}

In the section above we described the project manager's decision to trust individual team members to lead the project or parts of it temporarily and we noted a few criteria for trust (such as extraordinary skills, or good experiences in prior collaborations). The decision to trust (and subsequently empower the trustee) is made personally by the project manager, and is therefore an intra-personal decision of the vertical leader. Empirical evidence shows that trust is not absolute and depending on the level of trust, the vertical leader may choses different levels of acceptance of horizontal leadership. This can include blind acceptance of what the horizontal leader does; verification of the horizontal leader's 
actions by third parties, such as a validation by another team members or outside parties; review of the horizontal leader's actions by the project manager together with his or her supervisor; giving time for the horizontal leader to prove the viability of his or her actions; or the denial by the project manager. (Müller et al., 2016).

A precondition for being selected by the vertical leader is the potential horizontal leader's intrapersonal decision (i.e. leader intent) to put himself or herself up to a possible leadership position. The potential horizontal leader's positive decision supports his or her motivation for visible extraordinary performance, which is needed to become visible to the vertical leader as a potential candidate for horizontal leadership. This decision can be supported or hindered through a number of factors. Ample evidence exists that individuals often gradually take on more and more horizontal leadership roles until they can be considered a professional project manager, a phenomenon known as the accidental project manager (e.g. PMI, 2016). It describes the gradual role change from technical expert to leading technical expert, who, with increasing frequency, gets granted horizontal leadership authority until he or she is considered project manager and become formally appointed to this vertical leadership role. Another condition for a positive decision to become a horizontal leader is the person's belief that he or she has the abilities to successfully complete the task of horizontal leadership. This is known as selfefficacy and described by Bandura $(1977 ; 1982)$. Here one's capacity to represent future consequences of his or her actions provides a cognitively based source of motivation for a certain behavior. Selfefficacy comes to bear in the subsequent intra-personal decision whether one can successfully execute the behavior that leads to desired outcomes. A person's strength in the conviction that he or she can be effective in their activity affects "whether they will even try to cope with given situations" (Bandura, 1977, p. 193). That positions self-efficacy as a major aspect for prospective horizontal leaders in their decision to accept such a role or not.

The literature on leadership has a long tradition in addressing this aspect. The ability to build up selfefficacy in others is often described as a characteristic of successful (vertical) leaders and measured as part of assessment models, such as vertical leaders' competences in empowerment and in development as described by Dulewicz and Higgs (2003) in their cluster of MQ competence. Here empowerment is described as giving staff autonomy and to take on personally challenging tasks. It is often exhibited by encouraging others to solve problems, develop their own ideas and vision. Development is the vertical manager's belief that others have potential to take on ever more-demanding tasks and roles. These managers then coach and support people in the development of their competences, so that they can contribute effectively and develop themselves. (Dulewicz \& Higgs, 2005)

In summary, quadrant 1 describes the qualification and selection as preconditions for horizontal leadership to emerge. These are intra-personal (leading) activities and decisions by both vertical and horizontal leaders.

\section{(2) - Enabling horizontal leadership}

Quadrant 2 comprises of the vertical manager's inter-personal leadership activity of enabling horizontal leadership and announcing (or at least indicating) the potential horizontal leader. At the same time, it is the inter-personal leading of the horizontal leader towards a level of self-management that qualifies him or her for this role in the eyes of the other team members.

The way the vertical manger enables a horizontal leader to take over is a question of leadership style. Styles are known to be contingent on a number of factors, such as the personality of the vertical leader (as decribed above using the example of Dulewicz and Higgs (2003), the project type (Müller \& Turner, 2010a), project complexity (Turner \& Müller, 2006; Cavaleri \& Reed, 2008), the status of the project (e.g. Turner \& Müller, 2004), the national culture within which the project is executed (e.g. Müller \& Turner, 2004), to name a few. Developing a theory on the combination of all these factors would go beyond the scope of this chapter. However, we would like to point out the need for a careful evaluation of the situation by the vertical leader before enabling or announcing a candidate, as there might be rivalry candidates for the role of horizontal leader and the tension among them might reflect negatively on the performance of the team. 
For the horizontal leader candidate, the intra-personal self-leading towards a level that convinces others that they want to be led by the candidate marks this stage of the process. Self-leading is the process through which people influence themselves to achieve the self-direction and self-motivation needed to perform (Manz, 1986). Houghton, Neck and Manz (2003) describe it as being at the heart of shared leadership and done by individuals through devising strategies to influence and motivate themselves. The authors describe three categories of strategies:

- Behavior-focused strategies try to increase self-awareness for behavior needed to accomplish certain tasks. This is often done through self-observation, self-goal setting, self-reward, selfcorrecting feedback, and practicing.

- Natural (or intrinsic) reward strategies focus on the positive aspects of a task or its inherently rewarding aspects. This is often done by shifting the focus at work to the pleasant aspects of work.

- Constructive thought strategies influence and control the cognitive thought processes to facilitate the formation of constructive thought patterns or habits of thinking in order to impact positively on one's performance. This is often done through self-analysis and improvement of belief systems (i.e. identify, confront and replace dysfunctional beliefs and assumptions), mental imagery of successful performance outcomes, and positive self-talk (e.g. replacing discouraging self-talk with encouraging optimistic self-dialogs).

The three categories of self-leadership interact with self-efficacy and contribute to the enhancement of self-efficacy perceptions, which should lead to higher performance.

When the horizontal leader candidate reacts positively to the offer for leadership by the vertical leader, the next step in the process is reached.

\section{(3)-Exercising horizontal leadership}

At this stage of the process, vertical leadership is reduced and horizontal leadership increased. Here the vertical leader steps out of the limelight without surrendering the responsibility and accountability for appropriate leadership - project managers' responsibilities are part of established project governance structures and can be delegated but never transferred. Vertical leadership is still there, just not performed from the front row. At the same time, horizontal leadership steps in the limelight and leads in synchronization with vertical leadership.

The vertical leader reduces visible leadership, but is still involved in making sure that the project develops in the desired way. For that, the vertical leader facilitates the process of balancing vertical and horizontal leadership, monitors the horizontal leader(s), and ensures the presence of the leadership style(s) required for the project in its current situation. This may include traditional styles such as directive, transactional, or transformational (Houghton et al., 2003), or more contemporary leadership styles such as visionary, coaching, affiliative, democratic, pace-setting or commanding (Goleman, Boyatzis, \& McKee, 2002). Especially when appointing less experienced horizontal leaders it becomes important to establish the required support to allow the candidates to be successful.

The horizontal leader(s) accept the power, step(s) into the limelight, and attempt to exercise the leadership that they are appointed to. This is the time when horizontal leaders are most influential and visible. The experiences gained during this period shape the self-efficacy beliefs and attitudes that impact future decisions on accepting additional horizontal leadership opportunities, or even foster the desire to move into a management role in the future. As discussed above, the repetitive appointment to a temporary leadership role in projects often paves the way for team members to become formally appointed as project manager in the future.

\section{(4)- Monitoring and control}

This step is interwoven with step 3 in that it is the monitoring and control of the leadership exercised at step 3. For the vertical leader this includes the intra-personal leading activity of determining the scope, style and duration of horizontal leadership. For the horizontal leader it includes the implementation of monitoring and control as part of the inter-personal leadership he or she executes. 
At this stage the vertical leader leads him- or herself through a number of intra-personal decisions. These include: the amount of power to be granted to horizontal leaders and entire team, the frequency and extent of monitoring of the horizontal leader's activities, the ways of giving feedback, possible corrective actions, or the duration of the horizontal leadership. The amount of power refers to the degree the vertical leader steps back and leaves the field for the horizontal leader. Stepping back too much may be perceived by some vertical leaders as a sign of weakness or even a career limiting move. This needs to be balanced by the minimum level of power that is needed for the horizontal leader to be motivated to take on the task and being accepted by the team. Too little power reduces confidence and the desire to engage in horizontal leadership (Houghton et al., 2003). The monitoring and control must be in line with the level of power and the leadership style used. Claiming a high level of trust and then controlling on an hourly basis does not motivate or encourage the horizontal leader, especially not when done in front of the team. Feedback and possible corrective actions must also be adjusted in light of the power that is granted to the horizontal leader, possibly in personal talks rather than team meetings. Finally, the vertical leader must agree with the horizontal leader when to hand back the leadership to the vertical leader or to transfer it to another horizontal leader.

The horizontal leader's role at this stage is to implement a monitoring and control system as part of his or her leadership style. Do people follow him or her? Do they respect the horizontal leader? Is he or she really "in charge", or is the vertical leader (or someone else) actually leading the project? These types of questions must be addressed as part of the inter-personal leadership by the horizontal leader. An important aspect for that is the level of transparency in the project. The interaction between the two leadership roles (i.e. the balanced leadership) should be visible and understandable by the team members, so that the temporary transfer of leadership is a legitimate and transparent move for them. This includes transparency in possible changes in leadership styles, monitoring and control approaches (such as a switch from outcome to behavior control (Ouchi, 1980)), success factors, possible escalation procedures in case of problems with the temporary leader and so forth. Finally, transparency in the distribution of power and authority between the two leadership roles is a necessity for coordinated and predictable leadership during the time the horizontal leader is in charge.

The above process shows the interaction of intra-personal and inter-personal aspects of balanced leadership. It portrays balanced leadership as a four step process, where each step comprises different, albeit synchronized activities of the horizontal and vertical leaders. To that end, we addressed some of the limitations of existing literature, which often only take either an intra- or an inter-personal perspective, and showed the need for further studies to understand and theorize on the activities that go on in each of the four steps.

The process outlined here provides important insights for practitioners, such as the need for timely synchronization of the activities in each of the four steps, or the anticipation of the needs and activities of the subsequent step when executing balanced leadership. Moreover, it introduced the concept of balanced leadership, which is relatively new to the world of project management, but applicable at many layers in the organizational project management hierarchy or network. What has been described from the perspective of project manager as vertical leader and team member as horizontal leader is proposed to be equally applicable at, for example, for the program manager as vertical leader and the related project managers as horizontal leaders, as well as the portfolio manager with the respective program and project managers. To that end, we provided a new perspective to leadership in organizational project management, which will increase in importance due to the increasing specialization and diversity in projects.

We conclude that the process and systemic perspective of this chapter provides for a new and deeper understanding of the intra and interpersonal dynamics in balanced leadership: it is a first step towards a more holistic understanding of balanced leadership in projects. This contributes to the development of more realistic leadership theories, which provide for more deliberate and successful leadership approaches. 


\section{References}

Alvesson, M., \& Sveningsson, S. (2003a). The great disappearing act: Difficulties in doing "leadership". Leadership Quarterly, 14(3), 359-381.

Bandura, a. (1977). Toward a unifying theory of behavioral change. Psychological Review, 84(2), 191-215. doi:10.1037/0033-295X.84.2.191

Bandura, A. (1982). Self-efficacy mechanism in human agency. American Psychologist, 37(2), 122 147. doi:10.1037/0003-066X.37.2.122

Bass, B. M. (1990). Handbook of Leadership: Theory, Research and Applications . New York: Free Press.

Bennis, W., \& Nanus, B. (1985). Leaders: the strategies for taking charge. New-York: Harper and Row.

Blomquist, T., Hällgren, M., Nilsson, A. and Söder- holm, A. (2010) Project-as-Practice: In Search of Project Management Research that Matters. Project Management Journal, 41, 5-16.

Bolden, R. (2011). Distributed leadership in organizations: A review of theory and research. International Journal of Management Reviews, 13(3), 251-269.

Burke, C. S., Fiore, S. M., \& Salas, E. (2003). The Role of Shared Cognition in Enabling Shared Leadership and Team Adaptability. In C. L. Pearce \& J. A. Conger (Eds.), Shared Leadership (pp. 103-122). Thousand Oaks, CA, USA: SAGE Publications Inc.

Carroll, B., Levy, L., \& Richmond, D. (2008). Leadership as practice: Challenging the competency paradigm. Leadership, 4(4), 363-379.

Cicmil, S., Williams, T., Thomas, J. and Hodgson, D. (2006) Rethinking Project Management: Researching the Actuality of Projects. International Journal of Project Management, 24, 675-86

Collinson, D. (2000). Fifty Major Philosophers. LondOn, UK: Routledge.

Collinson, D., \& Collinson, M. (2009). "Blended leadership": Employee perspectives on effective leadership in the UK further education sector. Leadership, 5(3), $365-380$.

Cope, J., Kempster, S. and Parry, K. (2011). Exploring dis- tributed leadership in the small business context. Interna- tional Journal of Management Reviews, 13, pp. 270-285.

Cox, J. F., Pearce, C. L., \& Perry, M. L. (2003). Toward a Model of Shared Leadership and Distributed Influence in the Innovation Process: How Shared Leadership Can Enhance New Product Development Team Dynamics and Effectiveness. In C. L. Pearce \& J. A. Conger (Eds.), Shared Leadership (pp. 48-76). Thousand Oaks, CA, USA: SAGE Publications Inc, USA.

Cavaleri, S. \& Reed, F. (2008). Leading dynamically complex projects, International Journal of Managing Projects in Business, 1 (1), 71-87.

Crevani, L. (2015) Relational leadership. In: Carroll, Ford, Taylor (ed.), Leadership: Contemporary critical perspectives London: Sage Publications

Crevani, L., Lindgren, M., \& Packendorff, J. (2007). Shared leadership: A postheroic perspective on leadership as a collective construction. International Journal of Leadership Studies, 3(1), 40-67.

Crevani, L., Lindgren, M., \& Packendorff, J. (2010). Leadership, not leaders: On the study of leadership as practices and interactions. Scandinavian Journal of Management, 26(1), 77-86.

Cunliffe, A.L., \& Eriksen, M. (2011). Relational leadership. Human Relations, 64(11), 1425 - 1449.

Denis, J.-L., Lamothe, L., \& Langley, A. (2001). The dynamics of collective leadership and strategic change in pluralistic organizations. Academy of Management Journal, 44(4), 809-837. 
Denis, J. L., Langley, A., \& Sergi, V. (2012). Leadership in the plural. The Academy of Management Annals, 6(1), 211-283.

Drath, W., McCauley, C., Palus, C., Van Velsor, E., O’Connor, P., \& McGuire, J. (2008). Direction, alignment, commitment: Toward a more integrative ontology of leadership. Leadership Quarterly, 19(6), 635-653.

Dulewicz, V., \& Higgs, M. (2003). Leadership at the Top: The Need for Emotional Intelligence in Organizations. International Journal of Organizational Analysis, 11(3), 194-210.

Dulewicz, V., \& Higgs, M. (2005). Assessing leadership styles and organisational context. Journal of Managerial Psychology, 20(2), 105-123. doi:10.1108/02683940510579759

Endres, S., \& Weibler, J. (2016). Towards a Three-Component Model of Relational Social Constructionist Leadership: A Systematic Review and Critical Interpretive Synthesis. International Journal of Management Reviews, 00, n/a-n/a. doi:10.1111/ijmr.12095

Fletcher, J.K. (2004). The paradox of postheroic leadership: An essay on gender, power, and transformational change. Leadership Quarterly, 15(5), 647-661.

Gaddis, P. O. (1959). The Project Manager. Harvard Business Review, 1959(May-June), 89-97.

Goleman, D., Boyatzis, R., \& McKee, A. (2002). Primal Leadership: Learning to Lead with Emotional Intelligence. Boston, MA, USA: Harvard Business School Press.

Gronn, P. (2002). Distributed leadership as a unit of analysis. Leadership Quarterly, 13(4), 423-451.

Hansen, H., Ropo, A., \& Sauer, E. (2007). Aesthetic leadership. The Leadership Quarterly, 18(6), 544-560. doi:10.1016/j.leaqua.2007.09.003

Hauschildt, J., Keim, G., \& Medcof, J. W. (2000). Realistic Criteria for Project Manager Selection and Development. Project Management Journal, 31(3), 23-32.

Havermans, L.A., Den Hartog, D.N., Keegan, A. \& Uhl-Bien, M. (2015) Exploring the role of leadership in enabling contextual ambidexterity. Human Resource Management, 54(S1), s179s200.

Houghton, J. D., Neck, C. P., \& Manz, C. C. (2003). Self-Leadership and SuperLeadership. In C. L. Pearce \& J. A. Conger (Eds.), Shared Leadership (pp. 123-140). Thousand Oaks, CA, USA: SAGE Publications Inc, USA.

Huxham, C., \& Vangen, S. (2000). Leadership in the shaping and implementation agendas: How things happen in a collaboration (not quite) joined-up world. Academy of Management Journal, 43(6), 1159-1175.

Keegan, A., \& Den Hartog, D. N. (2004). Transformational leadership in a project-based environment: a comparative study of the leadership styles of project managers and line managers. International Journal of Project Management, 22(8), 609-618.

Lindgren, M. \& Packendorff, J. (2009). Project leadership revisited: Towards distributed leadership perspectives in project research. International Journal of Project Organisation and Management, 1(3), 285-308.

Lindgren, M., \& Packendorff, J. (2011). Issues, responsibilities and identities: A distributed leadership perspective on biotechnology R\&D management. Creativity and Innovation Management, 20(3), 157-170.

Manz, C. C. (1986). Self-Leadership: Toward an Expanded Theory of Self-Influence Processes in Organizations. Academy of Management Review, 11(3), 585. doi:10.2307/258312

Maslow, A. H. (1943). A Theory of Human Motivation. Psychological Review, 50(4), 370-396.

Mayer, R. C., Davis, J. H., \& Schoorman, F. D. (1995). An integrative model of organizational trust. Academy of Management Review, 20(3), 709-734. 
Mehra, A., Smith, B. R., Dixon, A. L., \& Robertson, B. (2006). Distributed leadership in teams: The network of leadership perceptions and team performance. The Leadership Quarterly, 17(3), 232245.

Müller, R., Nikolova, N., Sankaran, S., Zhu, F., Xu, X., Vaagaasar, A. L., \& Drouin, N. (2016). Leading Projects by Balancing Vertical and Horizontal Leadership -International Case Studies. In Proceedings of EURAM 2016 (European Academy of Management) Conference. June 1 - 4, 2016, Paris, France.

Müller, R., \& Turner, J. R. (2004). Cultural Differences in Project Owner - Manager Communication. In D. P. Slevin, D. L. Cleland, \& J. K. Pinto (Eds.), Innovations: Project Management Research 2004 (pp. 403-418). Newton Square, USA: Project Management Institute.

Müller, R., \& Turner, J. R. (2010a). Leadership competency profiles of successful project managers. International Journal of Project Management, 28(5), 437-448.

Müller, R., \& Turner, J. R. (2010b). Project-Oriented Leadership. (D. Dalcher, Ed.). Aldershot, UK: Gower Publishing.

Ouchi, W. G. (1980). Markets, Bureaucracies and Clans. Administrative Science Quarterly, 25, 129_ 141.

Packendorff, J., Crevani, L. \& Lindgren, M. (2014) Project leadership in becoming: A process study of an organizational change project. Project Management Journal, 45(3), 5-20.

Paoli, D. De, Vaagaasar, A., \& Müller, R. (2013). Project leadership and work space. In J. Söderlund \& R. Müller (Eds.), Proceedings of IRNOP XI (International Research Network for Organizing by Projects), June 16-17, 2013. Oslo, Norway.

Partington, D., Pellegrinelli, S., \& Young, M. (2005). Attributes and levels of programme management competence: an interpretive study. International Journal of Project Management, 23(2), 87-95.

Pearce, C. L., \& Conger, J. A. (2003). Shared Leadership. (J. L. Pearce \& J. A. Conger, Eds.). Thousand Oaks, CA, USA: SAGE Publications Inc, USA.

Pearce, J. L., \& Sims, H. P. (2000). Shared Leadership: Toward a Multi-Level Theory of Leadershippdf. In M. M. Beyerlein (Ed.), Team Development (7th ed., pp. 115-139). Elsevier Science Inc.

PMI. (2016). The accidental project manager. Retrieved January 1, 2016, from http://www.pmi.org/learning/professional-development/career-central/the-accidental-projectmanager.aspx

Raelin, J.A. (2011). From leadership-as-practice to leaderful practice. Leadership, 7(2), 195 - 211.

Sally, D. (2002). Co-leadership: Lessons from republican Rome. California Management Review, 44(4), 84-99.

Toor, S.-R., \& Ofori, G. (2008). Leadership for future construction industry: Agenda for authentic leadership. International Journal of Project Management, 26(6), 620-630. doi:10.1016/j.ijproman.2007.09.010

Turner, J. R. (2009). The handbook of project-based management: Leading strategic change in organisations. (J. R. Turner, Ed.) (3rd ed.). New York, NY, USA: MMcGraw-Hill.

Turner, J. R., \& Müller, R. (2004). Communication and Co-operation on Projects Between the Project Owner as Principal and the Project Manager as Agent. European Management Journal, 22(3), 327-336.

Turner, J. R., \& Müller, R. (2006). Choosing Appropriate Project Managers: Matching their leadership style to the type of project. Newtown Square; USA: Project Management Institute.

Uhl-Bien, M. (2006). Relational leadership theory: Exploring the social processes of leadership and organizing. Leadership Quarterly, 17(6), 654-676. 
